\title{
KARAKTERISTIK KEPEKATAN ASAP (OPACITY) MOTOR DIESEL DENGAN MENGGUNAKAN CATALYTIC CONVERTER ALUMINIUM
}

\author{
${ }^{1}$ Ahmad Robiul Awal Udin, ${ }^{2}$ Ahmad Fahriannur \\ ${ }^{1}$ Program Studi Mesin Otomotif , ${ }^{2}$ Program Studi Teknik Energi Terbarukan Jurusan Teknik \\ Politeknik Negeri Jember \\ Jalan Mastrip Kotak Pos 164 Jember \\ ahmadrobiulawal@gmail.com
}

\begin{abstract}
Abstrak
Jumlah penggunaan kendaraan bermotor yang terus bertambah untuk membantu dan memperlancar segala aktifitas manusia. Disisi lain kendaraan bermotor merupakan penyebab salah satu pencemar polusi udara terbesar. Dengan regulasi yang dikeluarkan pemerintah tentang standar emisi gas buang, maka perusahaan otomotif harus memenuhi ketentuan baku mutu emisi gas buang. Sehingga teknologi catalytic converter dijadikan salah satu solusi tepat untuk mengontrol dan mengurangi gas buang dari mesin kendaraan. Dalam proses pembakaran bahan bakar dan udara selain entalpi, produk sisa pembakaran yaitu emisi atau polutan $\mathrm{CO}, \mathrm{CO}_{2}, \mathrm{NOx}, \mathrm{HC}$, jelaga atau asap dan unsur - unsur lain yang dapat mencemari lingkungan dan dapat membahayakan kesehatan manusia. Pada motor diesel menghasilkan jelaga dan polutan gas NOx lebih banyak daripada motor bensin, namun menghasilkan $\mathrm{CO}_{2}$ lebih rendah. Dengan adanya catalytic converter berkatalis aluminium berlubang dan bersekat glaswool yang dipasang pada sistem exhaust manifold atau knalpot motor diesel dapat mengurangi emisi gas buang berupa asap hitam atau jelaga. Pengujian penelitian ini menggunakan metode eksperimental semu dengan membandingkan data gas buang yang dihasilkan motor diesel pada sistem exhaust manifold baik yang menggunakan maupun tanpa catalytic converter katalis aluminium berlubang. Pengambilan data dilakukan dikondisikan pada temperatur ruang saat pengujian. Pengujian dimulai pada putaran mesin diesel 1500 RPM sampai 2700 RPM dengan kenaikan putaran tiap 300 RPM. Hasil penggunaan catalytic converter sangat efektif dalam mengurangi kepekatan asap atau opacity dari motor diesel secara keseluruhan rata - rata sebesar 32,8 \%.
\end{abstract}

Kata kunci : Catalytic Converter, Emisi Gas Buang, Katalis Aluminium, Kepekatan Asap, Motor Diesel

\begin{abstract}
Total use of motor vehicles continues to grow to support and facilitate the activities of man. On the other hand motor vehicles is the cause of one of the biggest polluters of air pollution. With regulations issued by the government on exhaust emissions standards, the automotive company must comply with the quality standards of exhaust emissions. So that catalytic converter technology be one right solution to control and reduce the exhaust gases from the engine of the vehicle. In the process of combustion of fuel and air in addition to the enthalpy, residual products of combustion, namely emissions or pollutants $\mathrm{CO}, \mathrm{CO} 2, \mathrm{NOx}$, $\mathrm{HC}$, soot or smoke and elements - other elements that may pollute the environment and endanger human health. On diesel engine produces soot and gaseous pollutants NOx more than the gasoline engine, but produces lower $\mathrm{CO} 2$. With the catalytic converter perforated aluminum and insulated glaswool mounted on the exhaust manifold or exhaust system of a diesel engine can reduce exhaust emissions in the form of black smoke or soot. Testing this study using a quasi-experimental method by comparing the data of exhaust gas produced in the diesel motor exhaust manifold system either using or without catalytic converter perforated aluminum catalyst. Data were conditioned at room temperature while testing. The test starts at 1500 RPM diesel engine rev up to 2700 RPM to 300 RPM increment every round. The results of the use catalytic converters was very effective in reducing smoke density or opacity of the diesel engine as a whole the average by $32.8 \%$.
\end{abstract}

Keywords : Catalytic Converter, Emission, Aluminium Catalist, Opacity, Diesel Engine 
Ahmad Robiul Awal Udin, Ahmad Fahriannur, Karakteristik Kepekatan Asap (Opacity) Motor Diesel Dengan Menggunakan Catalytic Converter Aluminium

\section{PENDAhuluaN}

Pencemaran udara yang dominan sekitar $70 \%$ sebagai bahan pencemar yaitu emisi gas buang kendaraan bermotor. Emisi gas buang pada kendaraan motor diesel dan motor bensin dapat menimbulkan efek rumah kaca atau "global warming" dan gangguan kesehatan manusia dalam waktu jangka pendek atau panjang. Untuk mengurangi dampak negatif polusi asap kendaraan bermotor tersebut dibuatlah aturan atau regulasi yang mensyaratkan produsen otomotif untuk membuat teknologi kendaraan yang ramah lingkungan atau "go green", karena itu pemerintah menetapkan ambang batas emisi kendaraan bermotor dalam Peraturan Menteri Lingkungan Hidup No.05 Tahun 2006. Penggunaan teknologi yang dapat mereduksi emisi gas buang kendaraan yang berupa $\mathrm{CO}, \mathrm{HC}$ dan $\mathrm{NOx}$, salah satunya dengan menerapkan Catalytic Converter yang terpasang di sistem saluran gas buang (knalpot).

Catalytic Converter telah diaplikasikan pertama kali di USA pada tahun 1975. Secara garis besar prinsip kerja katalis konverter ini menguraikan dan mengubah kadar polutan secara reaksi kimiawi menjadi senyawa yang teroksidasi. Pengembangan catalytic converter untuk emisi gas buang motor diesel Selective Catalytic Reduction (SCR) dan Selective Non Catalytic Reduction (SNCR). Mokhtar (2014) menganalisa catalytic converter berbahan katalis plat tembaga yang berbentuk sarang lebah dapat mengoksidasi dan mereduksi kadar emisi CO sebesar 41,85\%, sedangkan untuk emisi $\mathrm{HC}$ turun sebesar $29,16 \%$, dan emisi $\mathrm{CO}_{2}$ turun sebesar $12,88 \%$. Pada penelitian catalytic converter ini akan mengembangkan metode SCR dengan tipe katalis aluminium berlapis serat glaswool terhumidifikasi, diharapkan dapat menurunkan kadar emisi gas dan mengurangi kepekatan (smoke) asap motor diesel.

Ambang batas untuk emisi gas buang kendaraan telah diatur oleh beberapa organisasi di dunia. Dalam mendukung usaha pelestarian lingkungan hidup, negara-negara di dunia mulai sumber pencemaran udara terbesar oleh menyadari bahwa gas buang kendaraan merupakan salah satu polutan.

Berdasarkan Peraturan Menteri Lingkungan Hidup Republik Indonesia Nomor 05 pada tahun 2006, dijelaskan bahwa ambang batas emisi gas buang kendaraan berbahan bakar solar atau diesel seperti pada tabel 1 .

Tabel 1. Tabel Opasitas Motor Bakar Diesel

\begin{tabular}{|l|c|c|c|}
\hline \multicolumn{1}{|c|}{ Kategori } & \multirow{2}{*}{$\begin{array}{c}\text { Tahum } \\
\text { Pembuatan }\end{array}$} & $\begin{array}{c}\text { Parameter } \\
\text { Opasitas } \\
\text { (\% HSU) * }\end{array}$ & \\
\hline Berpenggerak motor bakar & & & Percospatan \\
periyalaan kanpresi (diesel) & & & Bebas \\
- GW $\leq 3.5$ ton & $<2010$ & 70 & \\
& $\geq 2010$ & 40 & \\
- GWW $>3.5$ ton & $<2010$ & 70 & \\
& $\geq 2010$ & 50 & \\
\hline
\end{tabular}

\section{METODE}

Penelitian ini dilakukan berdasarkan tahapan yang menitikberatkan penggunaan catalytic converter dengan katalis aluminium untuk mereduksi kepekatan asap gas buang yang ditimbulkan dari proses pembakaran motor diesel. Model penelitian dengan menggunakan data metode pengujian eksperimental semu. Desain sistem catalytic converter dengan katalis aluminium dengan pemberian porforasi berlubang beridameter $2 \mathrm{~mm}$, yang diletakkan saling sejajar dengan jarak atau disekat (sesuai dengan gambar) dan diberi glaswool yang dijaga kelembapan dengan cara pengontrolan suhu melalui air yang diberi elemen pemanas atau koil heater. Objek penelitian menggunakan motor diesel 4 langkah (engine stand), dengan memanfaatkan knalpot atau muffler yang dipasang catalytic converter aluminium tersebut.

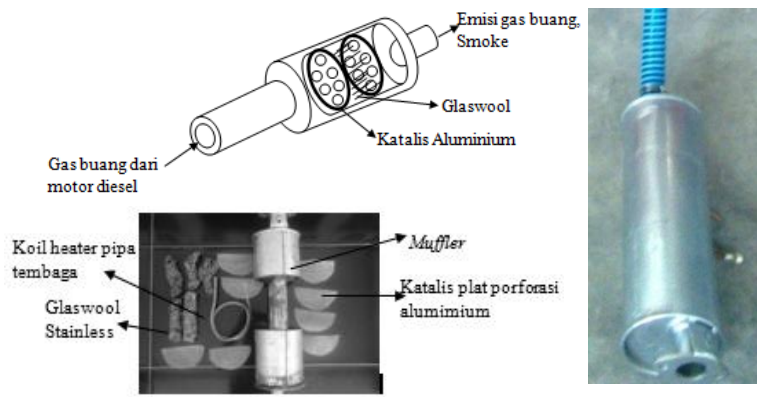

Gambar 2. Desain Catalytic Conveter Diesel

Untuk pengambilan data menggunakan pengamatan dengan alat Gas Analyzer for Diesel Portable secara empiris pada kondisi kendaraan mencapai temperatur optimal mesin yaitu $80^{\circ} \mathrm{C}$. temperatur pengujian disesuaikan dengan temperatur ruangan / lingkungan. Engine stand motor diesel memiliki pencatatan data secara terkomputerisasi yang dilengkapi alat ukur, Tachometer, Water and Air Temperature Sensor, Exhaust Temperature.

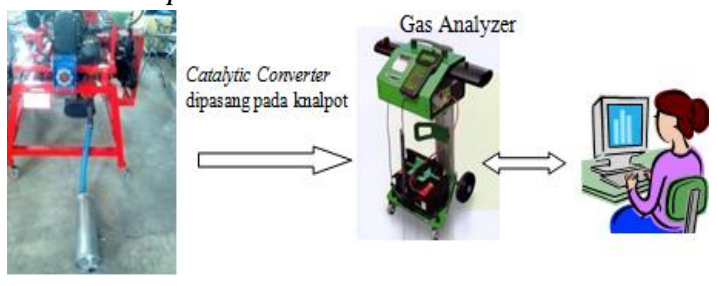

Gambar 3. Prosedur Pengujian

\section{HASIL DAN PEMBAHASAN}

Sebelum pengujian, terlebih dahulu dilakukan warm start pada mesin diesel dan inspeksi kemungkinan ada kerusakan selama 10 menit sampai mencapai suhu temperatur kerja mesin $80^{\circ} \mathrm{C}$. Berikut hasil pengujian seperti pada tabel 2. 
Tabel 2. Data hasil pengujian

\begin{tabular}{|c|c|c|c|c|c|}
\hline \multirow[b]{2}{*}{ No } & \multirow{2}{*}{$\begin{array}{c}\text { Putaran } \\
\text { mesin } \\
(\mathrm{rpm})\end{array}$} & \multicolumn{2}{|c|}{$\begin{array}{l}\text { Tanpa Catalytic } \\
\text { Converter }\end{array}$} & \multicolumn{2}{|c|}{$\begin{array}{l}\text { Dengan Catalytic } \\
\text { Converter }\end{array}$} \\
\hline & & $\begin{array}{c}\text { Opacity } \\
\text { Smoke } \\
(\%)\end{array}$ & $\begin{array}{l}\text { Opacity } \\
\text { Smoke } \\
\left(\mathrm{m}^{-1}\right)\end{array}$ & $\begin{array}{c}\text { Opacity } \\
\text { Smoke } \\
(\%)\end{array}$ & $\begin{array}{l}\text { Opacity } \\
\text { Smoke } \\
\left(\mathrm{m}^{-1}\right)\end{array}$ \\
\hline 1 & 1500 & 9,00 & 0,49 & 7,00 & 0,35 \\
\hline 2 & 1800 & 13,00 & 0,69 & 11,00 & 0,56 \\
\hline 3 & 2100 & 13,00 & 0,69 & 8,00 & 0,43 \\
\hline 4 & 2400 & 14,00 & 0,78 & 9,00 & 0,46 \\
\hline 5 & 2700 & 10,00 & 0,53 & 6,00 & 0,33 \\
\hline
\end{tabular}

Dari tabel diatas pada putaran mesin $1500 \mathrm{rpm}$ menghasilkan $9 \%$ Opacity Smoke untuk tanpa catalytic converter, sedangkan menggunakan catalytic converter $7 \%$ atau mengalami penurunan $22,22 \%$. Karena prinsip kerja alat Smoke Opacity meter berdasarkan sensor optic cahaya, jika terbaca $9 \%$ maka cahaya yang mampu ditembuskan oleh sensor optik $91 \%$ dan jika $7 \%$ cahaya yang bisa ditembuskan untuk diteruskan ke sinyal counter sebesar $93 \%$. Berikut tabel 3 prosentase penurunan tiap kenaikan rpm dengan membandingkan data yang menggunakan maupun tanpa catalytic converter $(C A T)$ :

Tabel 3. Prosentase Penurunan Kepekatan Asap

\begin{tabular}{|c|c|c|c|}
\hline No & $\begin{array}{c}\text { Putaran } \\
\text { mesin } \\
(\mathrm{rpm})\end{array}$ & $\begin{array}{c}\text { Prosentase } \\
\text { Penurunan } \\
\text { Opacity \% }\end{array}$ & $\begin{array}{c}\text { Prosentase } \\
\text { Penurunan } \\
\text { Opacity } 1 / \mathrm{m}\end{array}$ \\
\hline 1 & 1500 & 22,22 & 28,57143 \\
\hline 2 & 1800 & 15,38 & 18,84058 \\
\hline 3 & 2100 & 38,46 & 37,68116 \\
\hline 4 & 2400 & 35,71 & 41,02564 \\
\hline 5 & 2700 & 40 & 37,73585 \\
\hline
\end{tabular}

Gambar 4 memperlihatkan grafik perbedaan hasil pengujian kepekatan asap yang menggunakan catalytic converter (CAT) maupun yang tidak menggunakan, pada tiap perubahan dan kenaikan putaran mesin dengan satuan prosentase (\%).

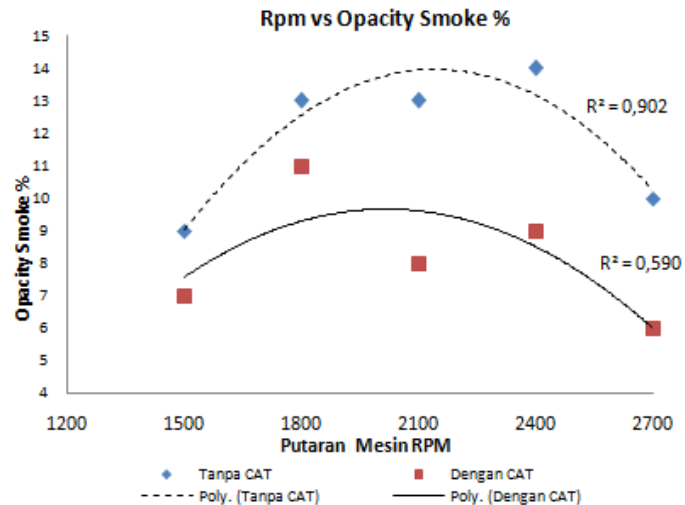

Gambar 4. Grafik Kepekatan Asap (\%) terhadap putaran mesin (Rpm)

Gambar 5 memperlihatkan grafik perbedaan hasil pengujian kepekatan asap yang menggunakan catalytic converter (CAT) maupun yang tidak menggunakan, pada tiap perubahan dan kenaikan putaran mesin dengan satuan per meter $(1 / \mathrm{m})$.

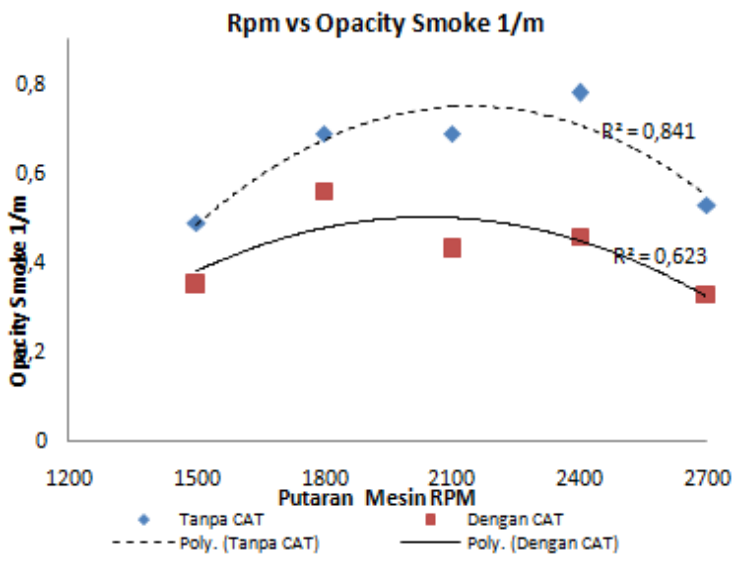

Gambar 5. Grafik Kepekatan Asap (1/m) terhadap putaran mesin (Rpm)

Dari gambar 5 dapat dijelaskan bahwa penggunaan catalityc converter mampu menurunkan kadar kepekatan secara keseluruhan dengan rata - rata sebesar $32,8 \%$, hal ini terlihat sangat signifikan pada putaran mesin $2400 \mathrm{rpm}$ dengan penurunan sebesar $41 \%$. Hal ini disebabkan karena efek dari reaksi antara Aluminium dengan gas buang motor diesel yang memiliki suhu $80-90^{\circ} \mathrm{C}$, sehingga akan memanaskan aluminium untuk mempercepat reaksi. Plat porforasi aluminium (berlubang - lubang kecil) yang ada di dalam muffler mampu mengurai dan menangkap jelaga gas buang motor diesel. Untuk opacity smoke dengan satuan $1 / \mathrm{m}$, dapat dijelaskan misalnya untuk putaran mesin $1500 \mathrm{rpm}$, memiliki opacity smoke 0,49 , berarti sensor membaca dan mengkonversi kepekatan asap sebesar 0,49 meter dari jangkaun total jarak 1 (satu) meter yang diukur. Gambar 4 dan 5 memiliki trend atau pola yang sama yaitu secara parabola terbuka kebawah dimana terjadi kenaikan kepekatan asap sampai puncak kemudian akan mengalami penurunan seiring kenaikan putaran mesin (rpm). Jika hasil penggunaan Catalytic Converter dibandingkan dengan ketetentuan Peraturan Menteri Lingkungan Hidup Republik Indonesia Nomor 05 tahun 2006, seperti pada tabel 4 berikut ini :

Tabel 4. Tabel Perbandingan Kepekatan Asap

\begin{tabular}{|c|c|c|c|}
\hline \multirow[b]{2}{*}{ No } & \multirow{2}{*}{$\begin{array}{l}\text { Putaran } \\
\text { mesin } \\
\text { (rpm) }\end{array}$} & Dengan CAT & \multirow{2}{*}{$\begin{array}{l}\text { PP LH No. } 5 \text { Tahun } 2006 \\
\text { Batas maksimal Opasitas } \\
\text { sebesar } 40 \%\end{array}$} \\
\hline & & $\begin{array}{l}\text { Opacity Smoke } \\
(\%)\end{array}$ & \\
\hline 1 & 1500 & 7,00 & Lebih rendah $33 \%$ \\
\hline 2 & 1800 & 11,00 & Lebih rendah $29 \%$ \\
\hline 3 & 2100 & 8,00 & Lebih rendah $32 \%$ \\
\hline 4 & 2400 & 9,00 & Lebih rendah $31 \%$ \\
\hline 5 & 2700 & 6,00 & Lebih rendah $34 \%$ \\
\hline
\end{tabular}

\section{KESIMPULAN}

Dari hasil penelitian yang dilakukan, dapat ditarik kesimpulan sebagai berikut :

1. Dengan penggunaan catalytic converter dengan katalis aluminium porforasi berlapis glaswool 
Ahmad Robiul Awal Udin, Ahmad Fahriannur, Karakteristik Kepekatan Asap (Opacity) Motor Diesel Dengan Menggunakan Catalytic Converter Alumunium

stainlees steel sangat efektif dalam mengurangi kepekatan asap atau opacity dari motor diesel secara keseluruhan rata - rata sebesar $32,8 \%$.

2. Pada putaran mesin $2700 \mathrm{rpm}$, kepekatan asap motor diesel sebesar $10 \%$ dan $0,531 / \mathrm{m}$ tanpa menggunakan catalytic converter, sedangkan kepekatan asap dengan menggunakan catalytic converter sebesar $6 \%$ dan $0,33 \quad 1 / \mathrm{m}$ atau mengalami penurunan $40 \%$.

\section{UCAPAN TERIMA KASIH}

Dengan selesainya penelitian ini, kami sampaikan terima kasih kepada Politeknik Negeri Jember melalui Pusat Penelitian dan Pengabdian Masyarakat Politeknik Negeri Jember melalui Program BOPTN tahun anggaran 2016.

\section{DAFTAR PUSTAKA}

[1] Arismundandar, Wiranto. 2005. Penggerak Mula Motor Bakar Torak edisi kelima. Penerbit ITB. Bandung

[2] Bennett, Sean. 2012. Modern Diesel Technology : Light Duty Diesels. Delmar : Cangage Learning. Clifton Park - New York USA.

[3] Faiz, Asif. 1996. Air Pollution From Motor Vehicles. The World Bank Washinton, DC. USA.

[4] Heywood, J. 2010. Internal Combustion Engine Fundamentals, MCGraw Hill.

[5] Mokhtar, Ali. 2014. Catalityc Converter Jenis Katalis Plat Tembaga Berbentuk Sarang Lebah Untuk Mengurangi Emisi Kendaraan Bermotor.Jurnal GAMMA Universitas Muhammadiyah Malang. Vol. 10, Nomor 1. September 2014.

[6] Peraturan Menteri Lingkungan Hidup No. 05 tahun 2006.

[7] Veeraragavan, V.2013. Fabrication and Testing of a Catalytic Convertor. International Journal of Application or Innovation in Engineering \& Management (IJAIEM). ISSN 2319 - 4847 (Online). Volume 2, Issue 11, November 2013. 